\title{
Rapeseed or linseed supplements in grass-based diets: Effects on milk fatty acid composition of Holstein cows over two consecutive lactations
}

\author{
S. Lerch, ${ }^{*}$ A. Ferlay, ${ }^{*}$ K. J. Shingfield, † B. Martin, ${ }^{*}$ D. Pomiès, ${ }^{*} \neq$ and Y. Chilliard ${ }^{* 1}$ \\ *INRA, UR1213 Herbivores, F63122 Saint-Genès Champanelle, France \\ †Animal Production Research, MTT Agrifood Research Finland, FI31600, Jokioinen, Finland \\ łINRA, UE1296 Monts d'Auvergne, F63210 Orcival, France
}

\section{ABSTRACT}

Persistency of changes in milk fatty acid (FA) composition to 4 different oilseed supplements rich in cis9 18:1 or 18:3n-3 was determined over 2 consecutive lactations in 58 and 35 Holstein cows during the first and second years, respectively. During the initial $5 \mathrm{wk}$ of the study, all experimental cows were fed the same diet. Thereafter, cows received 1 of 5 treatments for 2 consecutive lactations, including the prepartum period. Treatments comprised the basal diet with no additional lipid, or supplements of extruded linseeds (EL), extruded rapeseeds (ER), cold-pressed fat-rich rapeseed meal (FRM), or whole unprocessed rapeseeds (WR). Oilseeds were offered to provide between 2.5 to $3.0 \%$ of additional oil in diet dry matter. During indoor periods, cows received a mixture (3:1, wt/wt) of grass silage and grass hay, whereas cows were at pasture during outdoor periods. Over the entire study, oilseed supplements decreased the concentration of milk FA synthesized de novo and increased 18:0 and cis-9 18:1 content, with a ranking of treatment responses (highest to lowest) of FRM, EL, ER, and WR. Irrespective of period, both EL and FRM increased total milk trans FA content, whereas WR resulted in lower concentrations in milk from grazing cows. Relative to rapeseed, EL resulted in higher increases in milk cis-12,cis-15,trans-12 to -16 18:1, nonconjugated trans 18:2 (especially $\Delta 11,15$ ), and 18:3n-3. In contrast, rapeseed supplements resulted in a greater enrichment of cis-11 18:1, trans-4 to -9 18:1, and cis 20:1 than EL. Changes in milk FA composition to oilseeds were of greater magnitude during indoor than outdoor periods, where oilseed supplements often decreased cis-9,trans-11 conjugated linoleic acid content. During the second indoor period, both EL and ER resulted in higher total trans FA content, trans-10 18:1 in particular, than during the first indoor period, consistent with an interaction between dietary starch content and oilseed supplement. Overall, the extent of

Received January 12, 2012.

Accepted April 15, 2012

${ }^{1}$ Corresponding author: yves.chilliard@clermont.inra.fr changes in milk FA composition were related to the nature (rapeseed or linseed) and form of oilseed (extruded, cold-pressed fat-rich meal or whole unprocessed), and their interactions with the composition of the basal diet (grass silage and hay or pasture; or dietary starch content). Milk FA responses were stable within each period and repeatable over both outdoor feeding periods, with extent of changes being comparable to reports from relatively short-term (1- to 3-mo) studies.

Key words: bovine milk fatty acid, processed rapeseed, extruded linseed, long-term effect

\section{INTRODUCTION}

Dietary oilseed supplements decrease the concentration of 4- to 16-carbon SFA, increase 18:0, cis-9 18:1, cis-9,trans-11 conjugated linoleic acid (CLA), and may also enrich the 18:3n-3 content of bovine milk (Chilliard et al., 2007; Glasser et al., 2008a). Such effects can be considered as an improvement of the nutritional quality of milk, based on evidence from clinical studies indicating that excessive consumption of the medium-chain SFA 12:0, 14:0, and 16:0 FA elevates plasma low-density lipoprotein cholesterol, a known risk factor for cardiovascular disease, whereas 18:0 is considered neutral, and cis-9 18:1 and 18:3n-3 lower low-density lipoprotein cholesterol, contributing to a decrease in the incidence of human chronic disease (Shingfield et al., 2008). However, dietary oilseed supplements generally increase the concentration of trans FA in bovine milk (Glasser et al., 2008a), which, depending on the position and number of double bonds, may have detrimental effects on human health (Shingfield et al., 2008). Limited evidence exists to confirm putative adverse or neutral effects of trans 18:1 isomers from ruminant products relative to partially hydrogenated vegetable oils (Brouwer et al., 2010). Nevertheless, cis-9,trans-11 CLA exhibits potent antiinflammatory and anticarcinogenic activities, and is reported to improve biomarkers of cardiovascular health in animal models or studies with human cell lines (Shingfield et al., 2008). The effects of dietary oilseed supplements on bovine milk FA composition 
have been examined extensively in relatively short-term experiments of 1 to 3 mo in duration. Such studies have established that changes in milk FA composition vary according to the nature and form of oilseed supplement, as well as the composition of the basal diet (Chilliard et al., 2007; Glasser et al., 2008a). Among the different oilseeds used in dairy cow diets, linseeds enhance milk 18:3n-3 concentration, whereas increases in trans 18:1 due to dietary rapeseed supplements are lower compared with other oilseeds containing higher amounts of PUFA (Glasser et al., 2008a). Even though several studies have characterized milk FA responses to dietary supplements of extruded linseeds (EL) or ground rapeseeds (Chilliard et al., 2007), fewer studies have examined the effects of extruded rapeseeds (ER; Bayourthe et al., 2000; Neves et al., 2009) or cold-pressed fat-rich rapeseed meal (FRM; Mihhejev et al., 2007; Hristov et al., 2011). Furthermore, direct comparisons between rapeseed and linseed supplements, including a detailed description of changes in trans and cis isomers of unsaturated FA in cows fed grass-based diets are limited.

To develop production systems for the production of milk with altered FA composition, prior knowledge on the effect of dietary oilseed supplements on milk FA responses over an extended period is required. Relatively few experiments have reported the changes in milk FA to long-term dietary oilseed supplementation. Milk FA composition responses to ground or pelleted rapeseeds providing 2 to $4 \%$ additional oil of diet DM were considered to be stable and persistent in cows fed grass-based diets during 20 to 36 wk of lactation (Murphy et al., 1995; Moss, 2002; Fearon et al., 2004). However, conclusions on the changes in milk FA were based on milk iodine value (Fearon et al., 2004), or from the analysis of relatively few FA (Murphy et al., 1995; Moss, 2002) using GC techniques that do not allow specific trans and cis isomers to be resolved.

The objective of this study was to characterize milk FA composition responses to different natures of dietary oilseed supplements (EL or ER) or the form of rapeseed supplements (extruded seeds, cold-pressed fat-rich meal, or whole unprocessed seeds) over 2 consecutive lactations in cows fed diets based on grass silage and grass hay in the winter or at pasture in the summer. Furthermore, milk FA composition was determined using complimentary GC and GC-MS, allowing changes in the occurrence of minor FA to be characterized.

\section{MATERIALS AND METHODS}

\section{Animals and Diets}

Details of the design of the experiment have been reported previously (Lerch et al., 2012). In brief, the study was carried out on the experimental farm of Orcival from the Institut National de la Recherche Agronomique (INRA), located in a mountainous (1,000 $\mathrm{m}$ above sea level) region of Auvergne (Puy-deDôme, France). The experiment was conducted over 2 consecutive lactations. For each lactation, cows were housed indoors over winter and fed diets based on a mixture of grass silage and grass hay, or maintained outdoors on summer pasture during the second half of lactation.

Experiment $Y r$ 1. Fifty-eight Holstein cows were used (calving dates between October 13, 2007 and January 14, 2008). During the indoor period, cows were fed a mixture (3:1 on a DM basis) of conserved forages comprising grass silage and grass hay (Dactylis glomerata). For the outdoor period, cows were gradually turned out to pasture over a period of $1 \mathrm{wk}$, and then grazed for $20 \mathrm{~h} / \mathrm{d}$ from May 5, 2008 to October 27, 2008.

From calving until the end of the fifth week of lactation, all cows received a basal diet containing no oilseed supplements. Thereafter, cows were allocated to 1 of 5 groups according to calving date, parity, milk yield, and milk fat and protein content. Experimental concentrates were gradually introduced into the diet over a period of $4 \mathrm{wk}$ from the sixth week of lactation. A control concentrate contained pelleted wheat and solvent-extracted rapeseed meal (control, CTL), which was substituted for, in part, with EL [extruded blend (70:30, wt/wt) of linseeds and wheat; the mixture was extruded for $15 \mathrm{~s}$ at $100^{\circ} \mathrm{C}$ and then dried for $20 \mathrm{~min}$ at 125 to $145^{\circ} \mathrm{C}$; INZO ${ }^{\circ}$, Argentan, France], ER [extruded blend (59:29:12, wt/wt) of rapeseeds, wheat, and wheat bran; the mixture was extruded for $15 \mathrm{~s}$ at $100^{\circ} \mathrm{C}$ and then dried for $20 \mathrm{~min}$ at 125 to $145^{\circ} \mathrm{C}$; INZO ${ }^{\circ}$, FRM (a byproduct of cold pressure oil extraction; Dock Moulin SA, Marneffe, Belgium) or unprocessed, full-fat, uncrushed, whole rapeseeds $\left(\mathbf{W R}\right.$; INZO ${ }^{\circ}$ ). From the sixth week of lactation to the end of the indoor period, the amount of concentrate offered was adjusted weekly for each cow to maintain a 70:30 forage-to-concentrate ratio (on a DM basis). At pasture, each cow received $4.5 \mathrm{~kg}$ of experimental concentrate $\mathrm{DM} / \mathrm{d}$. During the dry period, cows received $4.5 \mathrm{~kg}$ of experimental concentrate DM of the same composition as fed during the outdoor grazing period.

Experiment $Y r$ 2. Thirty-five cows (calving dates between October 10, 2008 and February 13, 2009) continued in the trial for the second year. Cows were housed indoors and fed a mixture $(80: 20$, on a DM basis) of grass silage and grass hay (D. glomerata) from October 27, 2008 to May 4, 2009. Thereafter, cows were turned out to pasture (142 \pm 35 DIM; mean \pm SD) over a 1-wk transition period until November 3, 2009. 
After calving, the amount of concentrate offered was progressively increased during the first 5 wk. From the sixth week of lactation to the end of the second indoor period, the amount of concentrate offered was adjusted weekly to maintain a 60:40 (on a DM basis) forage-toconcentrate ratio. At pasture each cow received $4.5 \mathrm{~kg}$ of experimental concentrate DM.

Throughout the entire experimentation, the amounts of oilseed supplements were included in the diet to supply 3.0 and $2.5 \%$ of oil in diet DM during the indoor and outdoor periods, respectively. During indoor periods, forages were mixed daily and offered at $1000 \mathrm{~h}$ in amounts resulting in $10 \%$ refusals. Concentrates were prepared daily and offered in equal amounts at 1000 and $1730 \mathrm{~h}$ during indoor periods, and at 0700 and $1530 \mathrm{~h}$ during outdoor periods. Cows were milked at 0630 and $1600 \mathrm{~h}$ in a milking parlor. During indoor periods, cows were maintained in a freestall barn. Ingredient and chemical composition of concentrate mixtures fed throughout the experiment are reported elsewhere (Lerch et al., 2012).

\section{Sampling, Measurements, and Chemical Analyses}

Feeds. Individual forage and concentrate intakes were measured for each cow, during the last week of the preexperimental period (fifth week of lactation of the first year), twice during the first indoor period (72 \pm 17.0 and $141 \pm 23.1$ DIM; mean \pm SD), and twice during the second indoor period $(84 \pm 13.3$ and $129 \pm 35.0$ $\mathrm{DIM}$; mean $\pm \mathrm{SD}$ ), as described elsewhere (Lerch et al., 2012). On the same dates during the preexperimental and 2 indoor periods, twice during the first outdoor period $(197 \pm 23.1$ and $288 \pm 23.1$ DIM; mean \pm SD) and 3 times during the second outdoor period (171 \pm 35.0, $199 \pm 35.0$ and $262 \pm 35.0$ DIM; mean \pm SD), representative samples of forages and concentrates were collected (9 samples per feedstuff), stored at $-20^{\circ} \mathrm{C}$, lyophilized (Thermovac TM-20; Froilabo SA, Ozoir-laFerrière, France), and analyzed for NDF, ADF, starch (only for samples of pelleted wheat, and EL and ER concentrates) and ether extract (Lerch et al., 2012), and for the determination of FA composition.

Milk. During the same weeks when samples of feeds were collected, 1 subsample of unpreserved milk (60 $\mathrm{mL}$ ) was collected at morning milking. After storage for $28 \mathrm{~h}$ at $4^{\circ} \mathrm{C}$, milk FFA content was determined (Galilait, Theix, France) using the copper soap method (Jellema et al., 1991). At the same time, as well as for 1 additional week during the first outdoor period $(232 \pm 23.1$ DIM; mean \pm SD $)$, daily milk yield was recorded for each cow and subsamples of milk $(30 \mathrm{~mL})$ were collected over 4 consecutive milkings, preserved with bronopol B-2 (Trillaud, Surgères, France), stored at $4^{\circ} \mathrm{C}$, and analyzed for fat content (Galilait) by midinfrared spectrometry (AOAC, 1997; Milkoscan 4000; Foss Electric A/S; Hillerød, Denmark). Additional samples of unpreserved milk $(3 \mathrm{~mL})$ were collected over 2 consecutive milkings, stored at $-20^{\circ} \mathrm{C}$, lyophilized (Thermovac TM-20; Froilabo S.A.), and submitted for the determination of FA composition.

Lipid Analysis. Fatty acid methyl esters (FAME) were prepared from samples of ground lyophilized feeds using a one-step extraction and methylation procedure (Sukhija and Palmquist, 1988). The FAME recovered were analyzed by GC using a Trace-GC 2000 Series gas chromatograph equipped with a flame ionization detector (Thermo Finnigan, Les Ulis, France) and 100$\mathrm{m}$ fused silica capillary column (i.d. $0.25 \mathrm{~mm}$ ) coated with a $0.2-\mu \mathrm{m}$ film of cyanopropyl polysiloxane (CP-Sil 88; Chrompack Nederland BV, Middelburg, the Netherlands) and temperature gradient (Loor et al., 2004).

Lyophilized morning and evening milks were pooled (60 and $40 \mathrm{mg}$ of morning and evening samples, respectively) to provide a daily composite sample for each cow. Fatty acid methyl esters in 100-mg samples of lyophilized milk were prepared by direct methylation according to Ferlay et al. (2010) with modifications. In brief, samples were incubated with $2 \mathrm{~mL}$ of $0.5 \mathrm{M}$ sodium methoxide in anhydrous methanol plus $1 \mathrm{~mL}$ of hexane at $50^{\circ} \mathrm{C}$ for $15 \mathrm{~min}$, which, after cooling, was followed by the addition of $1 \mathrm{~mL}$ methanol/ $\mathrm{HCl}$ (95:5 vol/ vol) and incubation at $50^{\circ} \mathrm{C}$ for 15 min. Methyl esters were recovered in $1.5 \mathrm{~mL}$ of hexane, washed with $3 \mathrm{~mL}$ of aqueous ( $6 \% \mathrm{wt} / \mathrm{wt}) \mathrm{K}_{2} \mathrm{CO}_{3}$, and analyzed by GC. The total profile of FAME in a $0.6-\mu \mathrm{L}$ sample at a split ratio of 1:50 was determined using the same chromatograph equipped with the same column used for feed FA analysis. The injector temperature was maintained at $250^{\circ} \mathrm{C}$ and the detector temperature at $255^{\circ} \mathrm{C}$. Methyl esters were separated using a gradient program (initial oven temperature of $70^{\circ} \mathrm{C}$ held for $1 \mathrm{~min}$, increased to $100^{\circ} \mathrm{C}$ at a rate of $5^{\circ} \mathrm{C} / \mathrm{min}$, maintained for $2 \mathrm{~min}$, increased to $175^{\circ} \mathrm{C}$ at a rate of $10^{\circ} \mathrm{C} / \mathrm{min}$, held for $42 \mathrm{~min}$, and then increased by $5^{\circ} \mathrm{C} / \mathrm{min}$ to a final temperature of $225^{\circ} \mathrm{C}$ that was maintained for $22 \mathrm{~min}$ ). Hydrogen was used as the carrier and fuel gas. The injector pressure was held constant at $158.6 \mathrm{kPa}$. Peaks were routinely identified by retention time comparisons with commercial authentic standards containing a mixture of FAME (NCP \#463, Nu-Chek Prep Inc., Elysian, MN; Supelco \#37, Supelco Inc., Bellefonte, PA), in addition to methyl esters of geometric isomers of $\Delta 9,12$ 18:2 (L8404; Sigma, Steinheim, Germany), and positional and geometric isomers of CLA (O5632; Sigma). Correction factors to account for the carbon deficiency 
in the flame ionization detector response for FAME containing 4- to 10-carbon atoms were estimated using a reference butter oil of known composition (CRM 164; Commission of the European Communities, Community Bureau of Reference, Brussels, Belgium).

Methyl esters not available as commercial authentic standards, including cis-9 10:1, cis-9 12:1, trans-9 12:1, trans-5 15:1, cis-10,-13 16:1, trans-6,-7,-8,-11,-12,-14 16:1, cis-7,-8,-9 17:1, cis-10,-12,-13,-14,-15,-16 18:1, tra $n s-4,-5,-6,-7,-8,-10,-12,-13,-14,-15$ 18:1, cis-9, cis-15 18:2, cis-12,cis-15 18:2, cis-9,trans-13 18:2, cis-9,trans-14 18:2, trans-11,cis-15 18:2, trans-12,cis-15 18:2, trans11,trans-15 18:2, cis-9,-11 19:1, and 11-cyclohexyl 11:0 were identified based on electron impact ionization spectra of FAME and 4,4-dimethyloxazoline (DMOX) derivatives obtained by GC-MS. Preparation of DMOX derivatives, parameters used for GC-MS analysis, and interpretation mass spectra were in accordance with earlier reports (Halmemies-Beauchet-Filleau et al., 2011), with the exception that the temperature program applied during GC-MS analysis was identical to that used for the analysis of FAME by GC.

Sensory Analysis. From the beginning of the second outdoor period, milk samples collected on May 18, 25, 27, and June 3, 2009, from each group of cows were submitted to a trained 12 -member taste panel, with comparisons between samples being made according to standardized triangle tests. Raw milk subjected to sensory analysis was collected from the afternoon milking from each cow, pooled, and mixed to provide bulk composite samples for each treatment group. Once composited, 10-L subsamples were cooled and stored overnight at $4^{\circ} \mathrm{C}$ before being transported to the sensorial analysis laboratory of Aurillac (France) and analyzed using standard procedures (AFNOR, 1983). Once delivered, milk samples were heated to $32^{\circ} \mathrm{C}$, with $3(2$ identical, 1 unique) being dispensed into plastic glasses and evaluated under red light. Each panel member was requested to identify the unique samples and to describe perceived differences. Four comparisons were made (CTL vs. EL, CTL vs. ER, CTL vs. FRM, and CTL vs. WR) in each of the 4 sensorial test dates. Samples were allocated to taste panel members in a random sequence. For day of testing, 12 answers for each comparison were recorded.

\section{Calculations and Statistical Analyses}

Individual cow measurements of nutrient intake, milk yield, and milk composition were analyzed using the Mixed procedure for repeated measures of SAS (SAS Institute Inc., Cary, NC; 2003 version). A covariate term was calculated as the deviation between each in- dividual cow and the mean of its respective parity using data recorded during the fifth week of lactation of yr 1 . Experimental measurements were expressed as continuous variables relative to the average of lactation week for all the cows of the experimental herd at the time of sampling. Data recorded during indoor and outdoor periods were analyzed independently by ANOVA for repeated measures using a statistical model that included covariate, treatment, year, sampling date (defined as week within year), parity in the first year of experimentation within year, treatment by year, treatment by sampling within year, and parity in the first year by sampling within year interactions as fixed effects, and cow as a random effect. Because the interaction between parity in the first year and sampling within year was not significant, this term was removed from the model. To test the significance of interactions between treatment with indoor or outdoor periods, data from the first and second years of study were analyzed separately by ANOVA for repeated measures using a model that included covariate, treatment, period (indoor vs. outdoor), sampling within period, parity in the first year of experimentation, treatment by period, treatment by sampling within period and parity in the first year by sampling within period interactions as the fixed effects, and cow as a random effect. In all cases, a spatial power covariance structure was used. Least squares means are reported with pooled standard error of the mean derived from the model within period (indoor and outdoor). To comply with the assumptions of normality and homoscedasticity of residuals, statistical analysis of milk FFA concentrations was performed after logarithmic transformation. Least squares means and standard error of the mean were estimated from untransformed values, whereas $P$-values for treatment comparisons are based on the statistical analysis of transformed data.

Sensorial triangular test evaluations from each of the 12-member taste panel related to unique sample identification for all 4 preplanned comparisons on each test date were assigned as either correct or incorrect. Results were expressed as a percentage of correct responses and differences were tested statistically based on comparisons with values from the binomial law parameter $P=1 / 3$ with $\mathrm{n}$ repetitions (AFNOR, 1983).

Owing to the extensive amount of data generated in the present study, $P$-values for treatment effects are not stated in the following text. Changes in response to treatment (i.e., an increase or decrease) are described, when significant, at $P \leq 0.05$, or as a trend toward significance at $0.05<\bar{P} \leq 0.10$. The significance of treatment effects on all measured parameters are reported in the tables. 


\section{RESULTS}

\section{Intake, Milk Yield, and Composition}

Chemical composition of feed ingredients and nutrient intakes are reported in Tables 1 and 2, respectively. During the first indoor period, the $3 \%$ target oil level in diet DM from all oilseed treatments was achieved, but for the second indoor period, the amount of additional oil in the diet from oilseed supplements was higher than intended (Table 2). On average, oilseed supplements supplied $440,410,550$, and $460 \mathrm{~g}$ of oil/d during the first outdoor period and 490, 520, 430, and $650 \mathrm{~g}$ of oil/d during the second outdoor period for EL, ER, FRM, and WR, respectively. Decreases in forage DMI and total DMI were observed for EL, compared with ER and WR during the first indoor period, and compared with ER, FRM, and WR during the second indoor period (Table 2). During the second indoor period, forage and total DMI was lower for the CTL than FRM and WR. The proportion of concentrates in the diet increased, on average, from 30 to $41 \%$ of diet DM between the first and second indoor periods. As a result, mean dietary starch concentration increased from 6.8 to $16.8 \%$ in diet DM, whereas ADF concentration decreased from 26.1 to $23.3 \%$ in diet DM for the second compared with the first indoor period. Starch concentration in the diet increased more between the 2 indoor periods for EL, ER, and WR relative to the CTL and FRM (mean increases of $+14.9,10.2,11.1$, 7.8 , and $5.9 \mathrm{~g} / 100 \mathrm{~g}$, respectively; Table 2 ).

During the second indoor period, ER and FRM increased milk yield compared with CTL, EL, and WR. Milk fat content was lower for EL and ER than FRM and WR, whereas milk fat yield was higher for FRM compared with other treatments during the second indoor period (Table 3). During both outdoor periods, milk fat content was higher for WR relative to other treatments (Table 5).

\section{Milk FA Composition}

Treatment effects on milk FA composition during both indoor periods are presented in Tables 3 and 4 , and for both outdoor periods in Tables 5 and 6 , respectively. Changes in milk odd- and branched-chain FA (OBCFA) and minor isomers of 16:1 to treatments during the indoor and outdoor periods are reported in Supplementary Tables 1 and 2, respectively (available online at http://www.journalofdairyscience.org). Temporal changes in the concentrations of specific FA in milk or groups of FA over the course of the 2-yr experiment for all treatments are reported in Figures 1 to 3 .

\section{Effects of Oilseed Nature (EL vs. ER) During yr 1}

Indoor Period (Tables 3 and 4; Figures 1, 2, and 3; Supplementary Table 1). Compared with the CTL, EL and ER resulted in similar decreases in milk total SFA and OBCFA, and comparable increases in total cis 18:1 and trans 18:1 concentrations. However, total PUFA and trans FA concentrations in milk were increased more by EL than ER, whereas only EL increased total nonconjugated 18:2. Both EL and ER lowered the concentration of 6- to 17-carbon SFA. Conversely, EL and ER resulted in comparable increases in 18:0, whereas only ER increased 20:0 and 22:0. Milk concentrations of 10- to 17-carbon cis-9 MUFA were decreased, and cis-9 18:1 and cis-9 20:1 were elevated by EL and ER. Increase in milk cis-9 20:1 content was higher for ER than EL, with ER also causing an enrichment of cis-11 20:1. Supplements of EL, and ER to a lesser extent, increased 18:3n-3 and 20:4n-3, and decreased 18:2n-6 and 20:4n-6 concentrations.

Milk concentrations of numerous ruminal biohydrogenation (RBH) intermediates were increased by EL and ER. Concentrations of trans-11,-12 16:1, cis-12,-15,-16 18:1, trans-12,-13,-14,-16 18:1, all 18:2 isomers other than 18:2n-6, and cis-9,trans-11 CLA in milk were increased more by EL than ER. Conversely, trans-6,-7,-8 16:1, cis-11 18:1, and trans-4,-5,-6,-7,-8,-9 18:1 were increased to a greater extent by ER than EL. However, trans-10 18:1 was not affected, whereas cis-13 18:1 and trans-11 18:1 were increased to the same extent by both EL and ER.

Outdoor Period (Tables 5 and 6; Figures 1, 2, and 3; Supplementary Table 2). In comparison with the CTL, both EL and ER induced similar changes in milk FA composition, as measured during the indoor period, but the magnitude of decreases in total concentrations of SFA, cis 18:1, and MUFA concentrations (mean responses $-5.2,+4.4$, and $+4.6 \mathrm{~g} / 100 \mathrm{~g}$ of FA, respectively) were lower compared with the responses during the indoor period (corresponding values -10.0 , +7.7 , and $+8.9 \mathrm{~g} / 100 \mathrm{~g}$ of FA, respectively). However, milk total PUFA and trans FA concentrations were only increased by EL. All milk OBCFA concentrations (except 13:0 iso and 18:0 iso) were decreased by EL and ER. Milk cis-9 20:1 and cis-11 20:1 concentrations were increased by ER, whereas EL increased milk 18:3n-3, 20:4n-3, and 20:5n-3 content.

With the exception of trans-11 18:1, $\Delta 11,15$ 18:2, and cis-9,trans-11 CLA, both EL and ER induced similar alterations in the abundance of RBH intermediates as measured during the indoor period. However, the extent of changes in milk cis-11,-12,-15,-16 18:1, trans-16 18:1, and cis-12,cis-15 18:2 concentrations to both treatments were lower than observed during the indoor period. In 
Table 1. Chemical composition of forages and concentrates

\begin{tabular}{|c|c|c|c|c|c|c|c|c|c|c|c|}
\hline Item & \multicolumn{3}{|c|}{$\%$ of DM } & \multicolumn{8}{|c|}{$\mathrm{g} / 100 \mathrm{~g}$ of total FA } \\
\hline Grass silage & 44.3 & $\mathrm{ND}^{2}$ & 4.8 & 15.6 & 1.55 & 3.7 & 0.44 & 20.1 & 46.6 & 0.71 & ND \\
\hline Hay & 63.2 & ND & 1.6 & 27.4 & 2.99 & 4.2 & 1.08 & 14.5 & 31.7 & 1.80 & ND \\
\hline \multicolumn{12}{|l|}{ Concentrates ${ }^{3}$} \\
\hline FRM & 18.8 & 16.3 & 13.3 & 6.5 & 1.52 & 48.7 & 5.23 & 25.0 & 9.1 & 0.50 & 1.06 \\
\hline WR & $23.5^{4}$ & 6.9 & 13.2 & 5.8 & 1.43 & 52.1 & 4.75 & 22.5 & 9.6 & 0.48 & 1.00 \\
\hline \multicolumn{12}{|l|}{ yr 1 outdoor period ${ }^{5}$} \\
\hline June pasture & 41.6 & ND & 3.6 & 14.2 & 1.64 & 2.0 & 0.35 & 13.4 & 61.7 & 0.43 & ND \\
\hline September pasture & 43.0 & ND & 4.3 & 13.9 & 1.36 & 1.1 & 0.46 & 12.8 & 60.7 & 1.02 & ND \\
\hline \multicolumn{12}{|l|}{ Concentrates $^{3}$} \\
\hline \multicolumn{12}{|l|}{ yr 2 indoor period ${ }^{1}$} \\
\hline Grass silage & 57.8 & ND & 2.6 & 19.6 & 1.93 & 3.3 & 0.70 & 21.6 & 41.0 & 1.35 & ND \\
\hline Hay & 56.1 & ND & 1.8 & 22.8 & 2.13 & 2.2 & 0.47 & 12.9 & 46.6 & 1.25 & ND \\
\hline \multicolumn{12}{|l|}{ Concentrates ${ }^{3}$} \\
\hline CTL & 12.0 & 53.9 & 4.1 & 14.1 & 2.52 & 20.9 & 2.12 & 52.5 & 5.9 & 0.27 & 0.31 \\
\hline EL & 13.8 & 49.4 & 11.1 & 8.3 & 3.20 & 19.3 & 0.85 & 26.6 & 40.2 & 0.16 & 0.08 \\
\hline ER & 17.9 & 36.7 & 11.3 & 7.6 & 1.69 & 45.1 & 3.26 & 27.9 & 11.7 & 0.39 & 0.92 \\
\hline FRM & 18.2 & 26.4 & 10.6 & 7.8 & 1.58 & 44.3 & 4.60 & 28.5 & 10.0 & 0.42 & 0.99 \\
\hline WR & $15.4^{4}$ & 32.9 & 14.7 & 6.9 & 1.74 & 50.2 & 3.51 & 25.0 & 10.0 & 0.48 & 0.96 \\
\hline \multicolumn{12}{|l|}{ yr 2 outdoor period ${ }^{5}$} \\
\hline June pasture & 49.6 & ND & 2.0 & 17.9 & 1.57 & 2.6 & 0.39 & 13.5 & 55.9 & 0.53 & ND \\
\hline July pasture & 41.8 & ND & 2.9 & 16.0 & 1.24 & 1.6 & 0.23 & 13.4 & 59.9 & 0.47 & ND \\
\hline September pasture & 56.1 & ND & 3.0 & 14.4 & 1.18 & 1.5 & 0.37 & 10.9 & 65.0 & 0.47 & ND \\
\hline \multicolumn{12}{|l|}{ Concentrates $^{3}$} \\
\hline
\end{tabular}

${ }^{1}$ Cows received diets based on grass silage and grass hay supplemented with experimental concentrates (forage:concentrate ratio on a DM basis, 70:30 and 60:40, for yr 1 and 2, respectively).

${ }^{2} \mathrm{ND}=$ not determined.

${ }^{3}$ Concentrate mixtures contained pelleted wheat and solvent-extracted rapeseed meal (control, CTL), substituted for, in part, with an extruded blend of linseeds and wheat (70:30\% wt/wt; EL); extruded blend of rapeseeds, wheat, and wheat bran (59:29:12\% wt/wt; ER), cold-pressed fatrich rapeseed meal (FRM); or whole unprocessed rapeseeds (WR). The chemical composition of individual feed ingredients is reported elsewhere (Lerch et al., 2012).

${ }^{4}$ Estimated, based on published values (INRA, 2007).

${ }^{5}$ Cows were offered free access to pasture and $4.5 \mathrm{~kg}$ of experimental concentrate DM/d; yr $1=2007 / 2008 ;$ yr $2=2008 / 2009$.

contrast to the effects during the indoor period, ER decreased milk trans-11 $18: 1$ and $\Delta 11,15$ 18:2 content, whereas the occurrence of trans-11 18:1 was not altered by EL. Furthermore, cis-9, trans-11 CLA was decreased by EL, and substantially lowered in response to ER.

\section{Effects of Rapeseed Form (ER vs. FRM vs. WR) During yr 1}

Indoor Period (Tables 3 and 4; Figures 1, 2, and 3; Supplementary Table 1). During the first indoor period, FRM decreased to a greater extent 6- to 17-carbon SFA and cis-9 MUFA, total SFA and OBCFA, and resulted in higher increases in total cis 18:1, total MUFA, 18- to 22-carbon SFA, and cis-9 MUFA than ER. Treatment ER resulted in larger changes in milk FA composition compared with WR. Both FRM, and to a lesser extent ER, increased total trans 18:1, trans FA, and PUFA concentrations. Treatment FRM increased total milk nonconjugated 18:2 content, whereas WR decreased the concentrations of these FA. Only WR decreased 18:2n-6 in milk, whereas FRM 
was the only treatment to lower 20:3n-6 and 20:5n-3. Both ER and FRM resulted in comparable increases in 18:3n-3 and similar decreases in 20:4n-6 concentrations.

Concentrations of almost all RBH intermediates were increased by ER and FRM. In general, increases were of greater magnitude for FRM than ER, whereas the increase in milk trans-6,-7,-8 16:1, cis-11,-12,-13 18:1, trans-11 18:1, trans-11,trans-15 18:2, and cis-9,trans-11 CLA content were similar for ER and FRM. Nevertheless, only FRM increased trans-10 18:1, whereas ER was the only rapeseed treatment to enrich cis-12, cis-15 18:2 and trans-11,cis-15 18:2. Both ER and FRM decreased trans-12,cis-15 18:2. In contrast, WR resulted in marginal increases in trans-6,-7,-8 16:1, cis-11 18:1, trans-6,-7,-8,-9,-16 18:1, and trans-11,trans-15 18:2.

Outdoor Period (Tables 5 and 6; Figures 1, 2, and 3; Supplementary Table 2). Consistent with the changes during the indoor period, FRM, and to a lesser extent ER, decreased concentrations of 8- to 17-carbon SFA and cis-9 MUFA, total SFA and OBCFA, and increased total cis 18:1 and total MUFA concentrations. However, the magnitude of changes in milk fat to FRM and ER were lower than during the indoor period. All rapeseed treatments increased milk 18:0, cis-9 18:1, and 20:0 concentrations to a similar extent. During the outdoor period, only FRM increased total trans 18:1 and trans FA concentrations, whereas WR had no effect on total SFA and total MUFA, but decreased total trans 18:1, trans FA, and nonconjugated 18:2. All rapeseed treatments lowered 20:4n-6. Both FRM and WR decreased 18:2n-6, whereas decreases in 20:3n-6, 20:4n-3, and 20:5n-3 were exclusive to FRM. Milk 18:3n-3 content was not altered by rapeseed treatments during outdoor period.

Treatment FRM, and ER to a lesser extent, increased trans-6,-7,-8,-11,-12 16:1, all 18:1 isomers (other than trans-11 18:1), cis-9,trans-13 18:2, and cis-9,trans-14 18:2. Overall, when compared with the indoor period, those changes to ER and FRM were of lower and higher magnitude, respectively. Treatment WR resulted in marginal increases in cis-11 18:1 and trans-16 18:1, and decreased cis-12 18:1, cis-13 18:1, and trans-10 18:1. In contrast to the indoor period, trans-11,trans-15 18:2 was decreased by ER and FRM, whereas trans-11 18:1 and cis-9,trans-11 CLA were not affected by FRM but decreased by ER and WR.

\section{Effects of Oilseed Supplements During yr 2}

Indoor Period (Tables 3 and 4; Figures 1, 2, and 3; Supplementary Table 1). In general, milk produced during the second indoor period contained lower concentrations of total SFA and OBCFA and higher total trans FA and PUFA content compared with 
LONG-TERM OILSEED SUPPLEMENTS AND MILK FATTY ACIDS

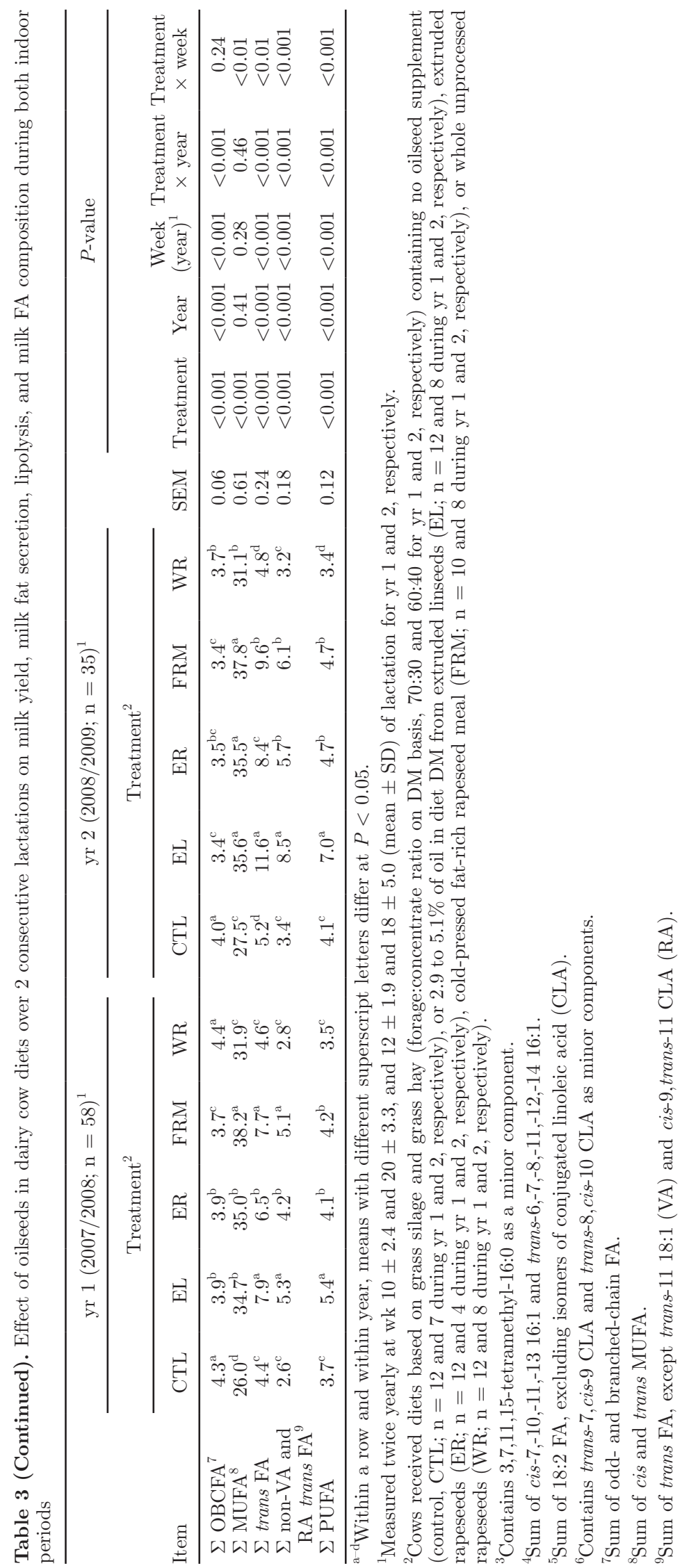




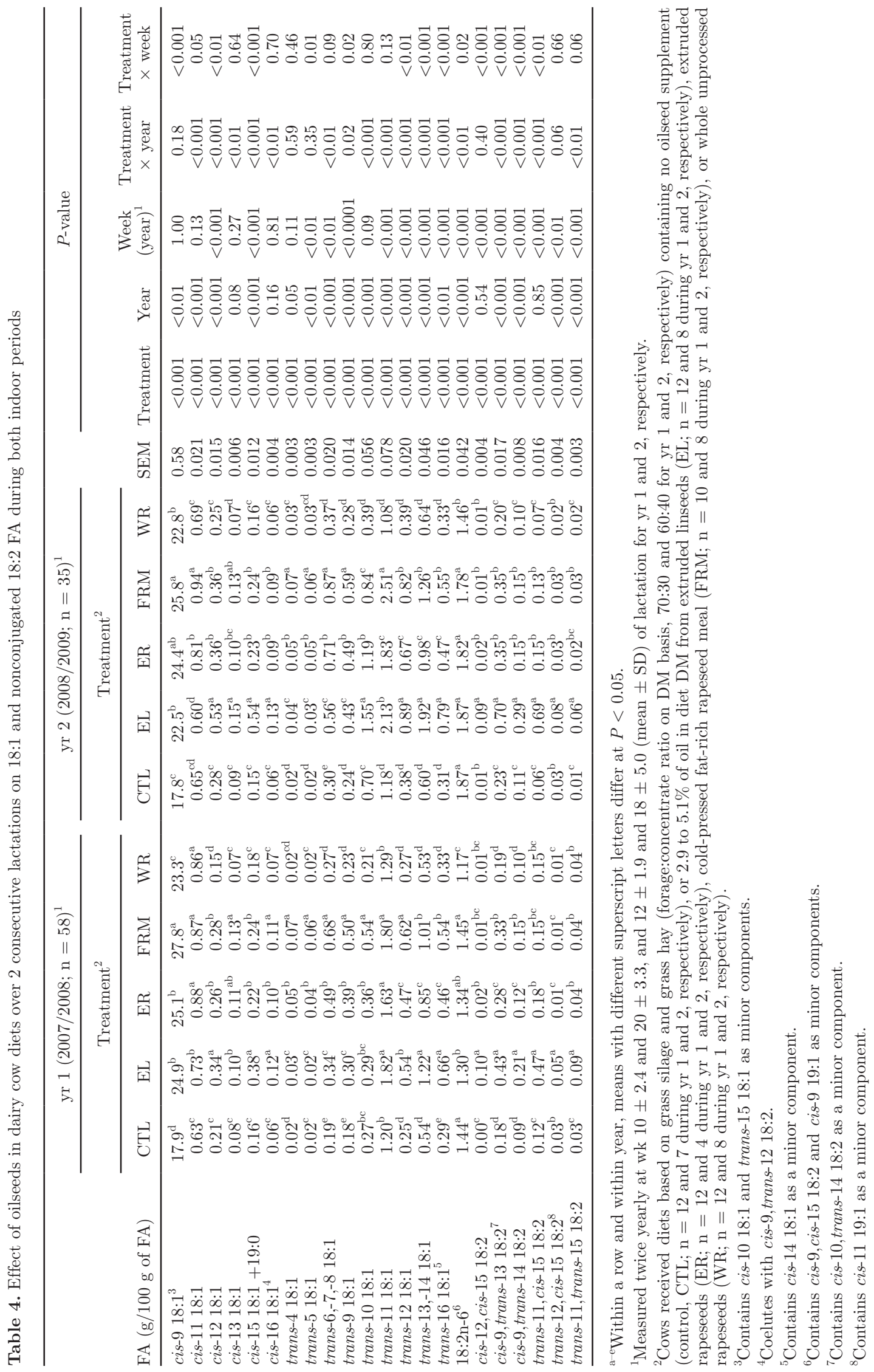


the first indoor period. Treatments had similar effects on milk total SFA and individual SFA (except 6:0, 8:0, 17:0, 18:0, 14- to 18-carbon iso FA, and 17:0 anteiso), total OBCFA, total MUFA, total cis 18:1, cis-9 18:1, and cis11 20:1 concentrations during the second than the first indoor period. However, in contrast to the first indoor period, WR decreased milk total OBCFA and PUFA concentrations. Furthermore, ER, FRM, and EL in particular, resulted in greater increases in milk total trans 18:1, trans FA, PUFA, and 18:3n-3, and larger decreases in 20:4n-6 during the second than the first indoor period. Moreover, 18:2n-6 was not decreased by EL.

Treatment EL, and ER to a lesser extent, increased trans-10 18:1, whereas WR decreased it. Overall, ER, FRM, and EL in particular, increased the concentration of other RBH intermediate concentrations (including trans-11 18:1 and cis-9,trans-11 CLA) to a greater extent during the second than the first indoor period. However, increases in cis-11 18:1, cis-16 18:1, and trans-11,trans-15 18:2 were lower. In contrast to the first indoor period, only milk trans-6,-7,-8 18:1 content was increased by WR.

Outdoor Period (Tables 5 and 6; Figures 1, 2, and 3; Supplementary Table 2). Treatments induced similar changes in milk total SFA, individual SFA (other than 4:0, 6:0, 7:0, 8:0, 11:0, 15:0 anteiso, 15:0 iso, 17:0 anteiso, and 20:0 for which effects were less pronounced), MUFA, and cis 18:1 concentrations during both outdoor feeding periods. However, compared with the first outdoor period, EL, ER, and FRM had less marked effects on milk total OBCFA, cis-9 20:1, cis-11 20:1, trans 18:1, and trans FA concentrations. Moreover, WR did not affect total OBCFA, but decreased total trans 18:1, trans 18:2, trans FA, and PUFA to a greater extent during the second than the first outdoor period. Additionally, concentrations of $18: 2 \mathrm{n}-6$ and n-3 PUFA were increased by EL to a greater extent during the second than first outdoor period.

In contrast to the first outdoor period, EL decreased trans-10 18:1, ER had no effect on it, whereas EL decreased cis-9,trans-11 CLA to a much greater extent. Increases in all other RBH intermediates to EL, ER, and FRM were lower during the second than the first outdoor period, with the exception of trans-6,-7,-8 16:1, cis-11,-12,-13 18:1, and trans-12,cis-15 18:2. Conversely, WR decreased trans-11,-12 16:1, cis-15 18:1, trans-6,-7,-8,-9,-12 18:1, cis-9,trans-13 18:2, and cis9,trans-14 18:2 in the second, but not the first outdoor feeding period.

\section{Lipolysis and Sensory Properties of Milk}

Irrespective of study year, milk FFA concentration after 28 -h storage at $4^{\circ} \mathrm{C}$ was higher during outdoor than indoor periods (Tables 3 and 5). Compared with the CTL, milk FFA concentration was lower for FRM and WR during the second indoor period; for WR during the first outdoor period; and for ER, FRM, and WR during the second outdoor period (Tables 3 and 5). During the second outdoor period, oilseed treatments had no significant effects on raw milk sensorial properties (texture and flavor) when compared with the CTL $(18,19,18$, and 17 correct answers out of a total of 48 , for EL, ER, FRM, and WR, respectively).

\section{DISCUSSION}

Effects of experimental treatments on feed intake, milk yield, and milk composition have been reported previously (Lerch et al., 2012). Although numerous experiments have examined the effect of oilseeds on milk FA composition (Chilliard et al., 2007), few have considered the persistency of these changes over an extended period. Novel aspects of the present study include a detailed assessment of the impact of dietary oilseed supplements on milk FA composition over 2 consecutive lactations.

\section{Milk FA Composition}

Effects of Indoor Versus Outdoor Period. Milk from cows housed indoors and fed conserved forages contained higher concentrations of SFA synthesized de novo and lower concentrations of unsaturated FA, cis-9 18:1, trans-11 18:1, and cis-9,trans-11 CLA in particular (Figures 1-3). These findings are in accordance with the known effect of grazing and forage conservation on milk FA composition (Chilliard et al., 2007).

Effects of Oilseed Nature (EL vs. ER) During yr 1. Both EL (3.2\% of added oil in DMI) and ER $(2.9 \%$ of added oil in DMI) consistently decreased FA synthesized de novo, total SFA, and OBCFA, and increased 18:0, total cis 18:1, trans 18:1, and MUFA concentrations (Figures 1-3). Changes in milk FA composition to EL during the indoor period were similar, but of higher magnitude compared with reports in cows fed hay-based diets supplemented with EL supplying $2.2 \%$ of oil in DM (Egger et al., 2007), but of lower magnitude relative to reports in cows fed corn silage- and corn/grass silage-based diets supplemented with EL supplying between 4.7 to $5.8 \%$ of oil in DM (Gonthier et al., 2005; Akraim et al., 2007; Chilliard et al., 2009; Ferlay et al., 2010). Supplements of ER (2.0\% of oil in DMI) of a corn silage-based diet (Bayourthe et al., 2000) were also reported to induce similar effects on milk fat composition, but the extent of alterations were lower compared with the ER treatment during the indoor period in the current study. Differences in the 


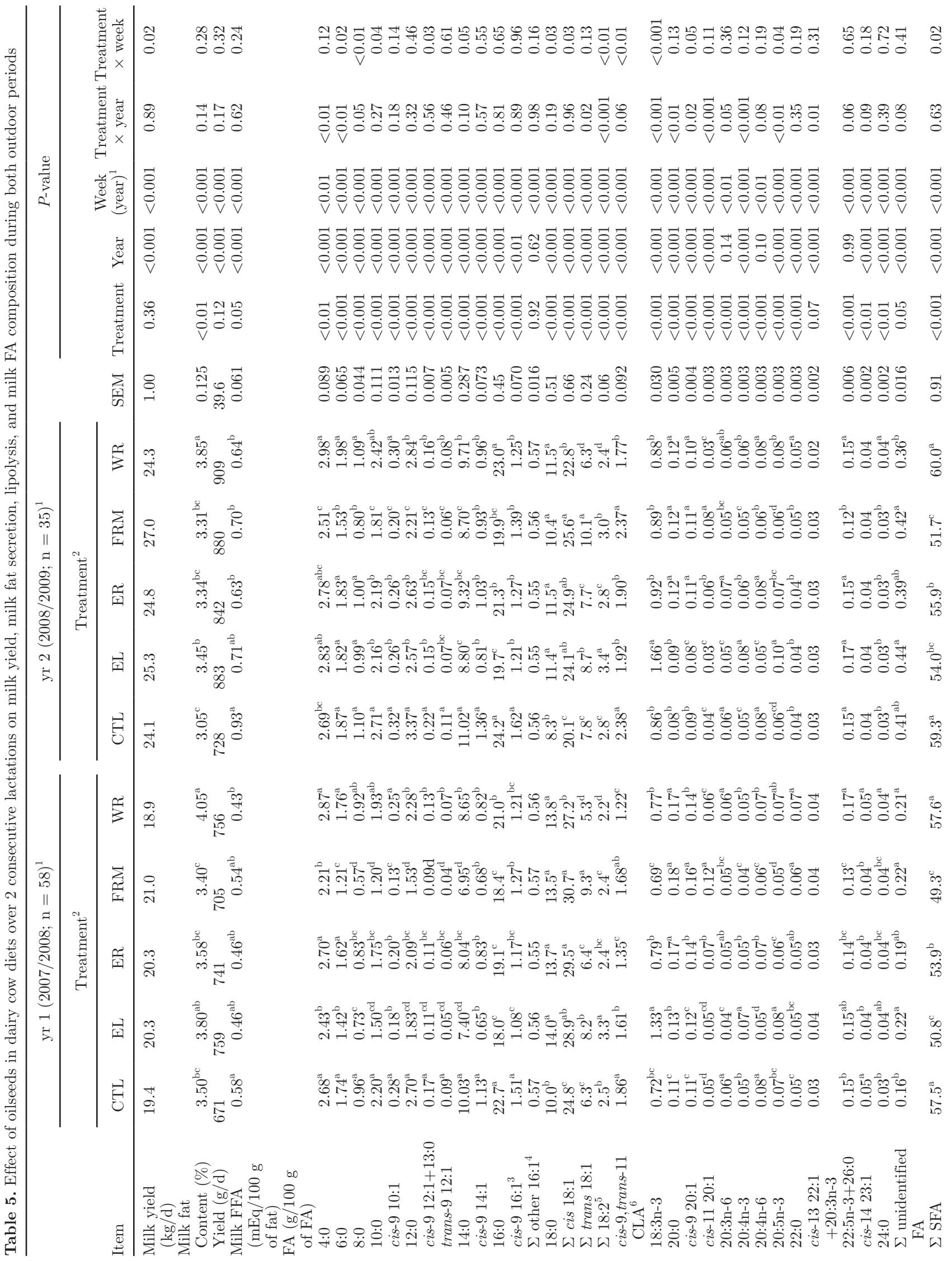


LONG-TERM OILSEED SUPPLEMENTS AND MILK FATTY ACIDS

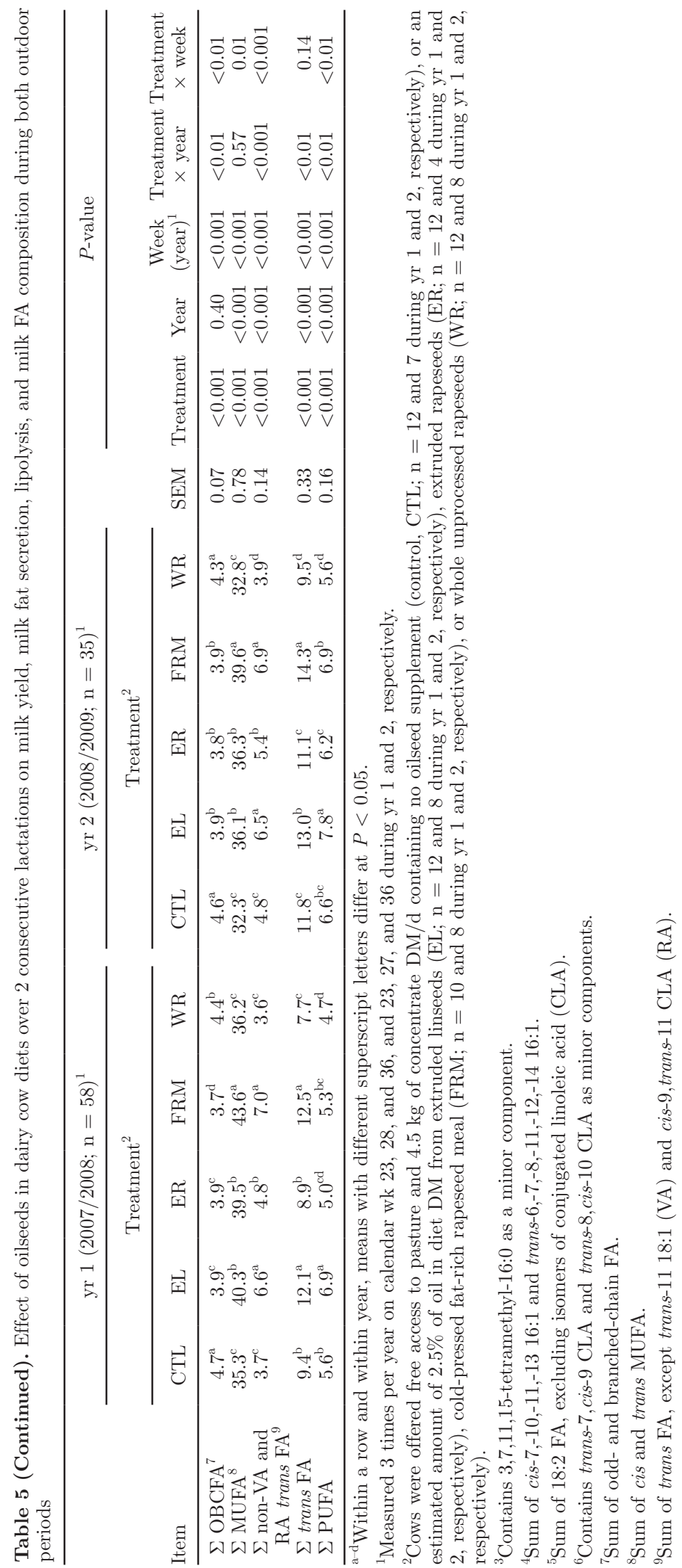




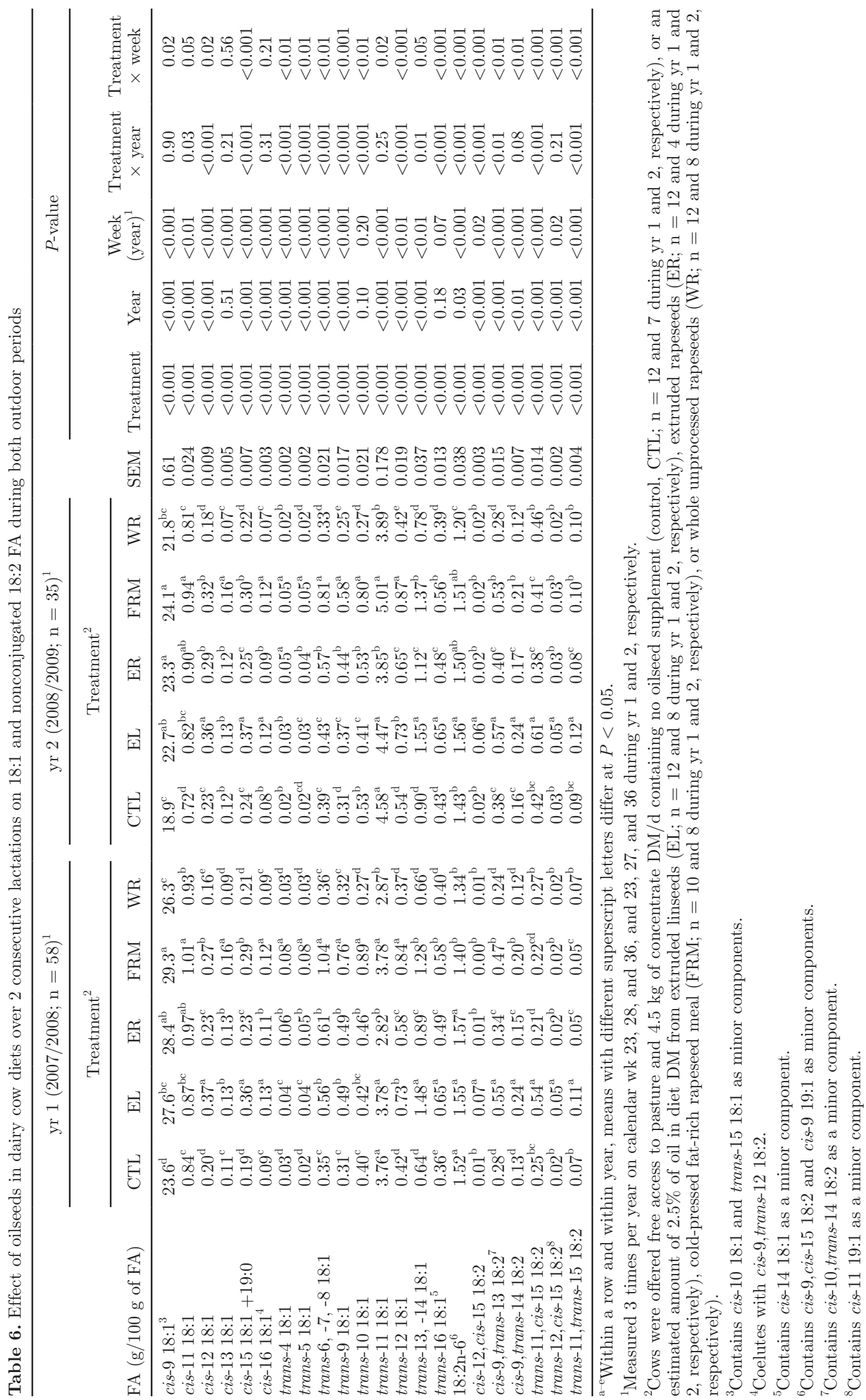



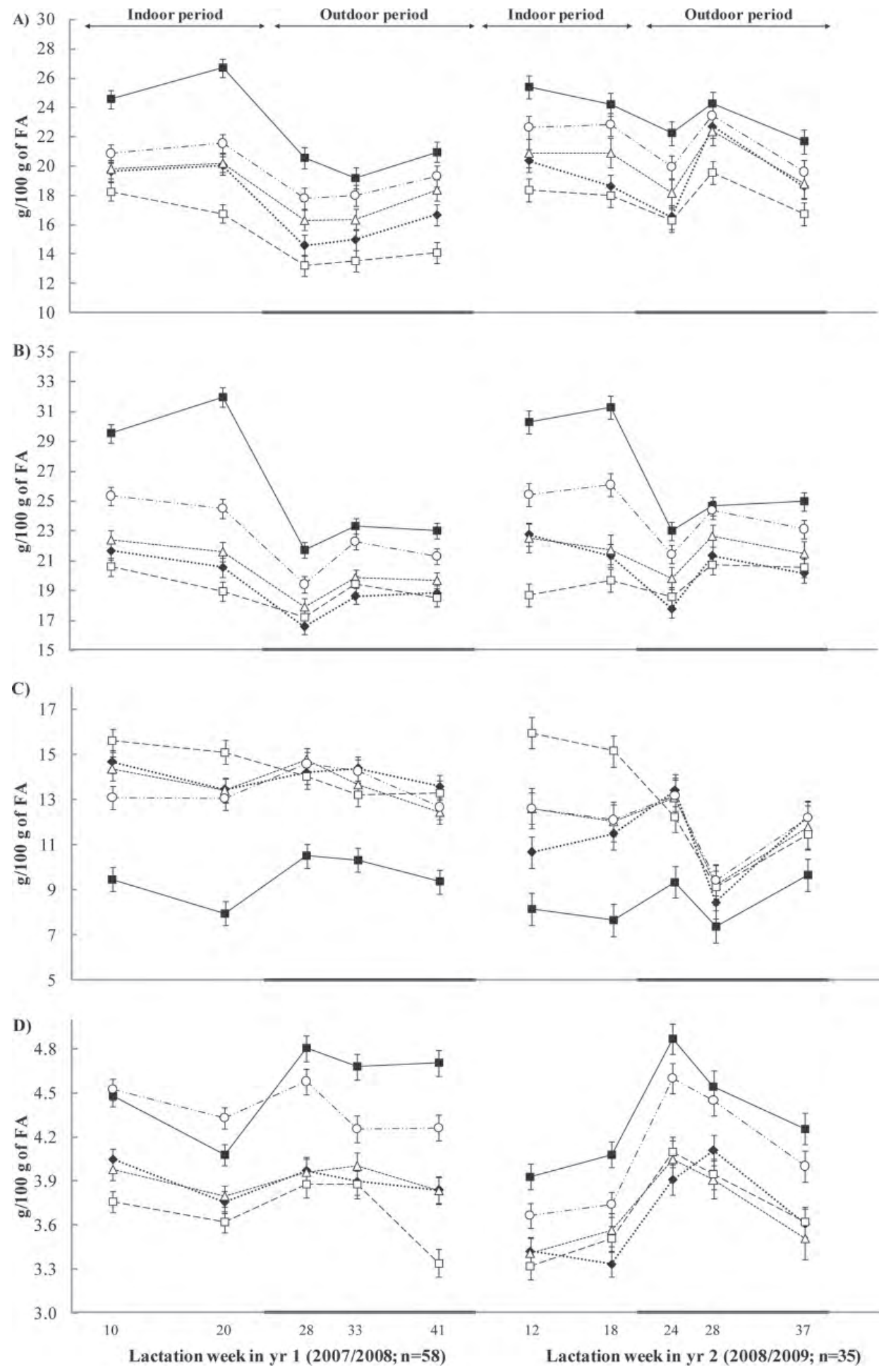

Figure 1. Concentrations of (A) the sum of 4:0, 6:0, 8:0, 10:0, 12:0, and 14:0, (B) 16:0, (C) 18:0, and (D) the sum of odd- and branchedchain FA in milk fat from cows housed indoors and fed grass silage and grass hay-based diets or maintained on pasture outdoors (bold x-axis line) over 2 consecutive lactations. Cows received diets containing no additional lipid (control diet, - $\mathbf{\square}$-; $\mathrm{n}=12$ during the first year and 7 during the second year), or 2.5 to $5.1 \%$ of oil in diet DM from extruded linseeds $(\cdots \cdots ; \mathrm{n}=12$ during the first year and 8 during the second year), extruded rapeseeds $(-\Delta-; \mathrm{n}=12$ during the first year and 4 during the second year), cold-pressed fat-rich rapeseed meal (-- $\square--; \mathrm{n}=10$ during the first year and 8 during the second year), or whole unprocessed rapeseeds $\left(-. .{ }^{\circ} \cdot{ }^{-} ; \mathrm{n}=12\right.$ during the first year and 8 during the second year). Each point represents treatment least squares means. Error bars indicate standard error of the mean calculated from 2 intraperiod (indoor and outdoor) statistical models (refer to Calculations and Statistical Analysis in the Materials and Methods section). $P$-values are reported in Tables 3 and 5 . 

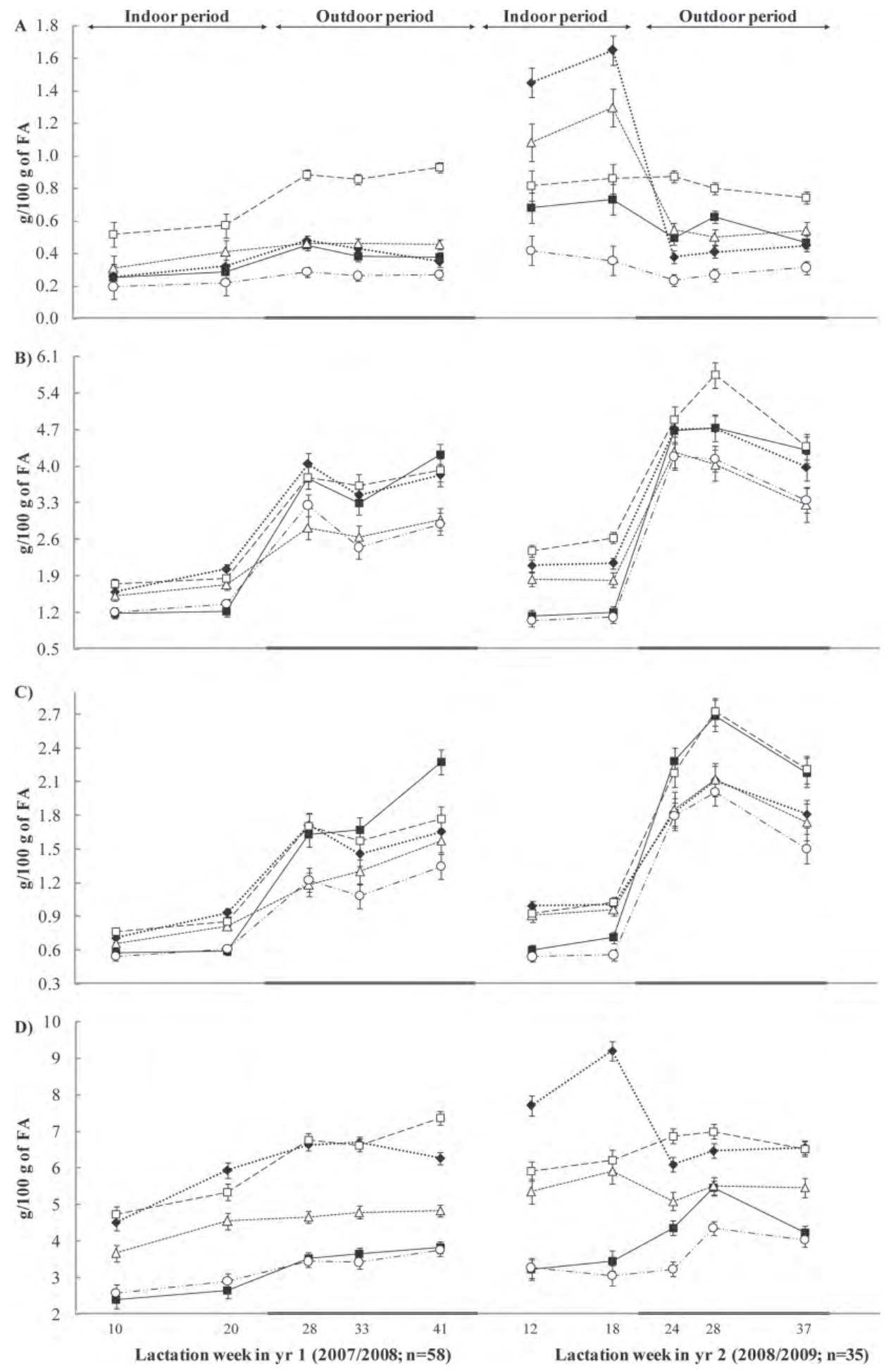

Figure 2. Concentrations of (A) trans-10 18:1, (B) trans-11 18:1, (C) cis-9, trans-11 conjugated linoleic acid (CLA), and (D) sum of trans FA (excluding trans-11 18:1 and cis-9,trans-11 CLA) in milk fat from cows housed indoors and fed grass silage and grass hay-based diets or maintained on pasture outdoors (bold x-axis line) over 2 consecutive lactations. Cows received diets containing no additional lipid (control diet,-; $\mathrm{n}=12$ during the first year and 7 during the second year), or 2.5 to $5.1 \%$ of oil in diet DM from extruded linseeds ( $\cdots \cdots ; n=12$ during the first year and 8 during the second year), extruded rapeseeds $(-\Delta-; \mathrm{n}=12$ during the first year and 4 during the second year), cold-pressed fat-rich rapeseed meal (-- $\square--; \mathrm{n}=10$ during the first year and 8 during the second year), or whole unprocessed rapeseeds $\left({ }^{-} \cdot . \mathrm{O}^{-\cdot-}\right.$; $\mathrm{n}=12$ during the first year and 8 during the second year). Each point represents treatment least squares means. Error bars indicate standard error of the mean calculated from 2 intraperiod (indoor and outdoor) statistical models (refer to Calculations and Statistical Analysis in the Materials and Methods section). $P$-values are reported in Tables 3 to 6 . 

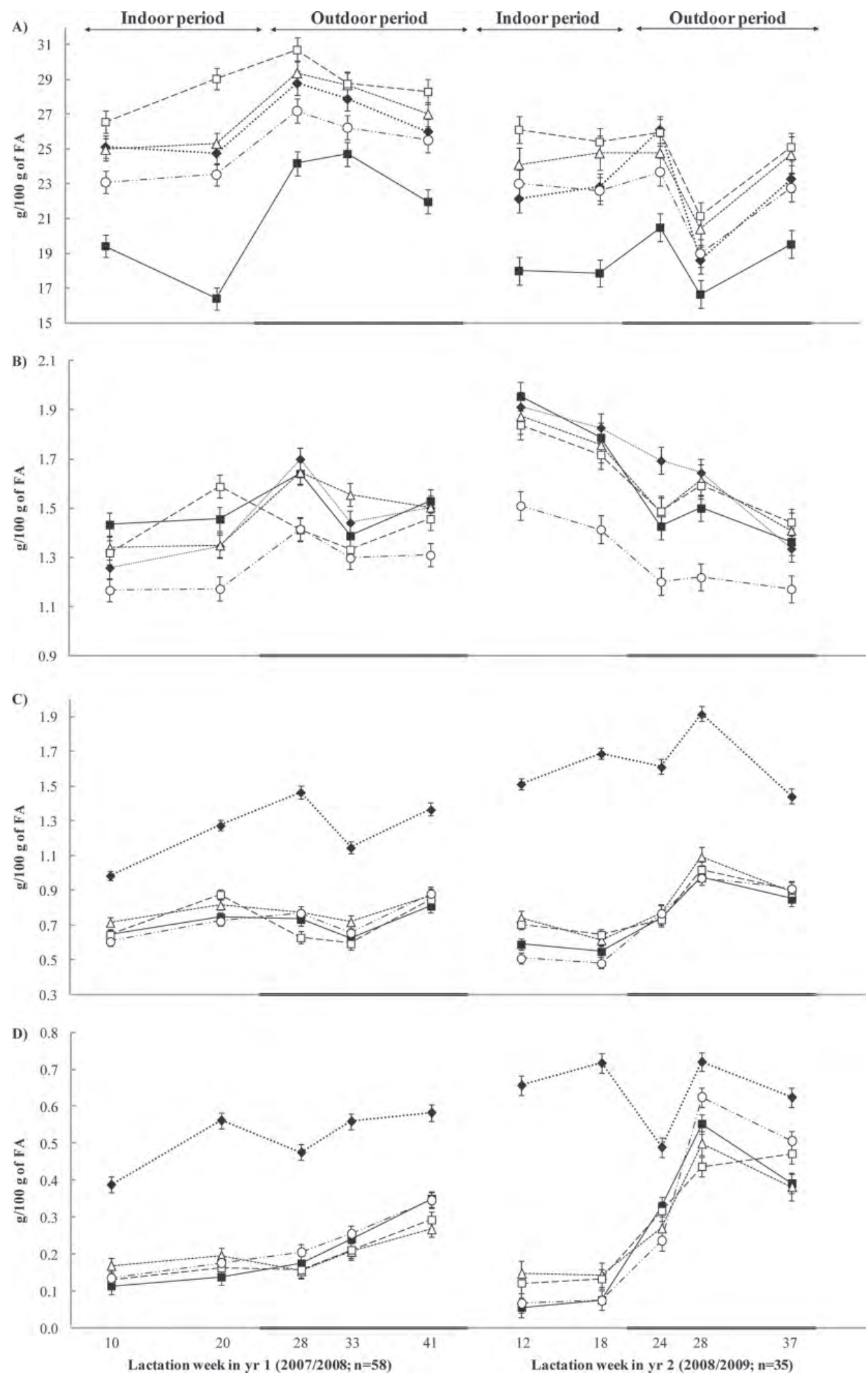

Figure 3. Concentrations of (A) cis-9 18:1, (B) 18:2n-6, (C) 18:3n-3, and (D) trans-11,cis-15 18:2 in milk fat from cows housed indoors and fed grass silage and grass hay-based diets or maintained on pasture outdoors (bold x-axis line) over 2 consecutive lactations. Cows received diets containing no additional lipid (control diet, - $\mathbf{\square}$-; $\mathrm{n}=12$ during the first year and 7 during the second year), or 2.5 to $5.1 \%$ of oil in diet DM from extruded linseeds $(\cdots, \cdots, n=12$ during the first year and 8 during the second year), extruded rapeseeds $(-\Delta-; \mathrm{n}=12$ during the first year and 4 during the second year), cold-pressed fat-rich rapeseed meal (-- $\square--; n=10$ during the first year and 8 during the second year), or whole unprocessed rapeseeds $(-. . \circ . .-; \mathrm{n}=12$ during the first year and 8 during the second year). Each point represents treatment least squares means. Error bars indicate standard error of the mean calculated from 2 intraperiod (indoor and outdoor) statistical models (refer to Calculations and Statistical Analysis in the Materials and Methods section). P-values are reported in Tables 3 to 6. 
magnitude of the responses between the present and earlier studies are probably related to both the level of supplementation and the composition of the basal diet. Thus far, no reports exist on the effect of EL or ER supplements on milk FA composition in grazing cows.

Supplements of EL increased milk trans-11,-12 16:1, cis-12,-15 18:1, trans-12 to trans-16 18:1, trans 18:2 (especially $\Delta 11,1518: 2$ ), and $18: 3 n-3$ to a greater extent than ER, whereas the reverse was true for milk trans-4 to trans-9 18:1 contents (Tables 3-6). Similar effects associated with the nature (linseed vs. rapeseed) of oilseed in the diet have been observed in cows fed conserved grass forages supplemented with ground seeds or fat-rich meals (Collomb et al., 2004; Mihhejev et al., 2007 ), or due to dietary oil supplements in cows at pasture (Rego et al., 2009). The effect of oilseed nature on milk 18-carbon FA composition can, at least in part, be explained by differences in the profile of intermediates formed during the RBH of cis-9 18:1 and 18:3n-3 in the rumen (Palmquist et al., 2005; Shingfield et al., 2010) that, after absorption, serve as substrates for milk fat synthesis. Furthermore, ER increased 20:0, cis-9 20:1, and cis-11 20:1 to a greater extent than EL (Tables 3 and 5) consistent with earlier reports (Collomb et al., 2004; Rego et al., 2009), which arises from the higher 20:0 and cis-11 20:1 content of rapeseed than linseed.

The effect of both EL and ER on milk FA synthesized de novo and 18-carbon FA composition was lower during the outdoor than indoor period (Figures 1-3). This could be explained, at least in part, by the lower amount of oil provided from oilseed supplements during the outdoor than indoor period (440 vs. 410 and 595 vs. $574 \mathrm{~g}$ of oil/d from EL vs. ER during outdoor and indoor periods, respectively). Compared with the CTL during the indoor period, the decreases in milk FA synthesized de novo and the increases in 18-carbon FA induced by both pasture feeding and EL or ER supplementation were only partially additive. This may be related to the content of total 18-carbon FA in milk being unable to exceed a threshold estimated as ca. $52 \%$ of total FA (Glasser et al., 2008b). It has been suggested that such a limitation arises from an intrinsic requirement for a high proportion of short-chain FA to be esterified at sn-3 during the final assembly of milk fat triacylglycerides (Glasser et al., 2008b). However, in the present study, the total 18-carbon FA content of milk fat in cows fed EL and ER during the outdoor period (57.4 and $54.1 \%$ of FA, respectively) exceeded this notional threshold, without decreasing milk fat content and yield.

Compared with the CTL, ER decreased milk trans-11 18:1, whereas EL and ER decreased cis-9,trans-11 CLA at pasture. However, other RBH intermediates in milk (especially cis-12 18:1, cis-15 18:1, and trans-13,-14
18:1) were increased with EL and ER compared with the CTL (Tables 5 and 6; Figure 2). Possible differences in pasture intakes across treatments could, at least in part, explain this discrepancy, but it was not possible to measure DMI of cows during the outdoor periods. It is also possible these changes in milk FA reflected the lower content of highly fermentable starch (especially from pelleted wheat) in the EL and ER concentrates relative to the CTL $(-30.1$ and $-28.5 \%$ on a DM basis, respectively; Table 1), which may have contributed to a more extensive reduction of trans-11 18:1 to 18:0 in the rumen. Indeed, intakes of trans-11 18:1 precursors from the diet were relatively high even for the CTL diet [predicted combined intakes of 18:2n-6 and 18:3n-3 according to INRA (2007) and analysis of feed samples of 330,580 , and $430 \mathrm{~g} / \mathrm{d}$ for CTL, EL, and ER, respectively]. A relatively high ingestion of PUFA on the CTL diet, combined with a higher starch content, may account for the greater abundance of trans-11 18:1 plus cis-9,trans-11 CLA in milk for the CTL compared with EL and ER treatments. However, the responses to ER in the present experiment differ from previous studies (Stanton et al., 1997, Lawless et al., 1998, Fearon et al., 2004), where supplements of ground or pelleted rapeseeds (400 to $600 \mathrm{~g}$ of added oil/d) increased milk cis-9,trans-11 CLA content in grazing cows. Discrepancies on the role of oilseed supplements on milk fat CLA content between this and earlier experiments may be related to differences in the amount and quality of fresh grass ingested, cows being offered pasture as the sole feed (Stanton et al., 1997), or the use of concentrates containing no (Lawless et al., 1998) or low amounts of starch (Fearon et al., 2004).

Effects of Rapeseed Form (ER vs. FRM vs. WR) During yr 1. During the outdoor period, changes in milk FA composition to all rapeseed treatments persisted over a 13-wk period (Figures 1-3) consistent with reports of stable milk iodine values over $18 \mathrm{wk}$ in cows at pasture supplemented with pelleted rapeseeds (Fearon et al., 2004).

For both indoor and outdoor periods, rapeseed treatments decreased milk FA synthesized de novo, and increased 18:0 and total cis 18:1 content. In addition, FRM and, to a lesser extent, ER decreased total OBCFA in milk, and increased total (non-trans-11 18:1 and non-cis-9,trans-11 CLA) trans FA concentrations (Tables 3 and 5; Figures 1-2). Similar changes, but of lower magnitude, have been reported for FRM (Mihhejev et al., 2007) and WR (Murphy et al., 1990) supplements in cows fed grass silage-based diets. Larger responses in the present experiment are probably due to the higher amount of oil supplied from oilseeds of 3.2 to $3.7 \%$ compared with 2.5 to $2.7 \%$ in earlier investigations (Murphy et al., 1990; Mihhejev et al., 2007). 
In the present study, direct comparisons indicated that rapeseed treatments resulted in similar alterations in milk FA composition, but the extent of changes to FRM was higher than for ER and WR. Such differences may, at least in part, be explained by the higher supply of oil from FRM relative to ER and WR $(3.7,3.2$, and $3.2 \%$ of oil in DMI during the indoor period, and 550, 410 , and $460 \mathrm{~g} / \mathrm{d}$ of oil during the outdoor period for FRM, ER, and WR, respectively). However, this in isolation may not fully account for the observed changes in milk FA composition. It is probable that oil from FRM may be more available in the rumen compared with extruded or whole rapeseeds, a finding supported by the higher concentrations of RBH intermediates and the lower concentrations of OBCFA in milk for FRM. The same explanation may also hold true for the observed differences in milk FA responses to ER and WR. Oil from whole rapeseeds is known to be released slowly in the rumen, owing to the resistance of the lignified seed coat to ruminal degradation (Murphy et al., 1990). Such a phenomenon may account for supplements of processed rapeseeds (milled, ground, or extruded) induce larger changes in milk FA composition than intact rapeseeds (Murphy et al., 1990; Bayourthe et al., 2000; Givens et al., 2009). Responses to rapeseed treatments in the present experiment are also in agreement with the ranking (largest to smallest) of decreases in de novo FA and OBCFA, and increases in 18:0, total cis 18:1, and trans FA in milk to linseed oil, extruded linseeds, and whole intact linseeds (Chilliard et al., 2009).

Among the rapeseed supplements fed in the outdoor period, only the FRM treatment maintained rather than decreased milk trans-11 18:1 and cis-9,trans-11 CLA content (Tables 5 and 6; Figure 2). This could be related to differences in pasture intake, or the level of highly fermentable starch contained in pelleted wheat being 3 times higher in FRM than ER and WR concentrates and, thus, closer in composition to the CTL treatment. As a consequence, rumen environment may well have been more similar between FRM and the CTL, leading to fewer changes in the extent of trans-11 18:1 accumulation or reduction in the rumen compared with other rapeseed treatments.

Effects of Oilseed During yr 2. The effects of oilseed treatments on milk FA composition persisted over the indoor (6-wk) and outdoor (13-wk) periods (Figures 1-3). Changes in milk FA composition to supplements of ground rapeseeds (3.1\% of added oil in DMI) in cows fed grass silage-based diets have been reported to be maintained over a 21-wk period (Moss, 2002), but the determination of milk fat composition only included 5 individual FA and 2 classes of FA.

Milk produced during the second indoor period contained higher concentrations of trans FA compared with the first indoor period (Table 3; Figure 2). The extent of differences between indoor periods was greatest for EL, and higher for ER than FRM. Compared with the CTL, ER and especially EL, increased milk trans-10 18:1 and 18:3n-3 to a greater extent and enriched 18:0 to a lesser extent during the second than first indoor period (Tables 3 and 4; Figures 1-3). These differences cannot be entirely explained by marginal differences in the amount of oil supplied from EL and ER between the 2 indoor periods $(+0.3 \%$ and $+0.7 \%$ for EL and ER, respectively). It is possible that interactions between oilseed supplements and dietary starch content may be responsible. A higher dietary starch content for CTL, ER, and EL in particular, may have induced a lower rumen $\mathrm{pH}$ during the second than first indoor period (Lerch et al., 2012). This suggestion is supported by a lower concentration of 14:0 iso in milk during the second than first indoor period, based on recent reports that decrease in 14:0 iso concentration in milk is associated with a low rumen $\mathrm{pH}$ (Fievez et al., 2012). Decreases in rumen $\mathrm{pH}$ can affect both the type and activity of bacteria capable of $\mathrm{RBH}$, decrease the extent of 18:3n-3 biohydrogenation, increase trans 18:1, and trans 18:2 accumulation, and promote trans-10 18:1 production (Palmquist et al., 2005). Earlier studies have provided clear evidence of a strong interaction between dietary linseed oil (3\% of oil in DM) supplementation and dietary starch (6.6 vs. $21.1 \%$ in DM) content (Loor et al., 2005). The extent of interactions between linseed supplementation and dietary starch content determined in the present and an earlier study (Loor et al., 2005) are also in line with recent observations in which linseed oil caused a larger increase in milk trans 18:1 concentration than extruded linseeds (Chilliard et al., 2009).

Oilseed treatments had similar, but marginally lower effects on milk FA during the second than the first outdoor period (Tables 5 and 6; Figures 1-3). Interactions between year and treatments could be explained by a higher pasture intake during the second than the first outdoor period because the increase in the average parity of the herd was probably associated with an increase in DMI (INRA, 2007), as could be expected by the higher milk production during the second than first outdoor period $(+4.7 \mathrm{~kg} / \mathrm{d}$ per cow for CTL; Table 5$)$.

\section{Lipolysis and Sensory Properties of Milk}

Irrespective of study year, milk FFA concentrations after 28 -h storage at $4{ }^{\circ} \mathrm{C}$ were higher during the outdoor than indoor periods (Tables 3 and 5). These differences are probably unrelated to dietary forage source, as milk fat lipolysis was reported to be higher for diets containing grass silage compared with pasture or grass hay 
(Chazal et al., 1987). It is probable that more extensive lipolysis of fat identified for milk produced at pasture is related to the more advanced stage of lactation or pregnancy, or both (Chazal and Chilliard, 1986), rather than due to differences in diet composition.

During the second year, all rapeseed treatments decreased milk fat lipolysis, in accordance with the known effects of dietary plant oil supplements (Chilliard and Lamberet, 1984). However, EL did not affect milk fat lipolysis in the present study, whereas higher amounts of EL (5.0\% of oil in DMI; Ferlay et al., 2010) supplements in cows fed corn silage-based diets lowered this parameter [S. Lerch, A. Ferlay, B. Graulet (INRA UR1213, Saint-Genès Champanelle, France), P. Pradel (INRA UE1296, Orcival, France), I. VerdierMetz (INRA UR545 Fromagères, Aurillac, France), Y. Chilliard, and B. Martin, unpublished data].

For the second outdoor period, treatments had no effect on the sensorial properties of raw milk, despite the differences in milk fat unsaturated FA content and extent of milk fat lipolysis. These results are consistent with no changes in the sensory attributes of milk in response to supplements of formaldehyde-treated rapeseeds (3\% of oil in diet DM) of concentrate-based diets (Urquhart et al., 1984) or EL supplementation (5\% of oil in diet DM) of corn silage-based diets (Martin et al., 2009).

\section{CONCLUSIONS}

Dietary oilseed supplements altered milk FA composition, changes that persisted over 2 consecutive lactations, and reproducible between both outdoor periods. Within each period, EL and ER induced similar decreases in FA synthesized de novo and total OBCFA, and comparable increases in 18:0 and cis-9 18:1 relative to the CTL. However, EL resulted in higher enrichment of 18:3n-3, cis-9,trans-11 CLA (only during indoor periods), and total trans FA compared with ER. Distribution of cis 18:1, trans 18:1, and 18:2 nonconjugated isomers was dependent on the nature of oilseed, but for rapeseed supplements independent of processing. Similar effects on milk FA composition were observed for all rapeseed treatments, but the magnitude of changes was highest for FRM, and greater for ER than WR. Important and biologically significant interactions between the composition of the basal diet (preserved grass vs. pasture; starch content in the diet) and oilseed supplements were observed. During the outdoor periods, EL, ER, and WR treatments decreased milk cis-9,trans-11 CLA content compared with the CTL, possibly due to lower dietary starch content. Furthermore, the higher starch content of diets during the second indoor period appeared to explain the larger increase in total trans FA, particularly trans-10 18:1, in milk from cows fed the EL and ER treatments. Oilseed supplements examined in this study may improve the nutritional value of milk fat, particularly in cows fed diets based on conserved forages containing relatively low amounts of starch. Nevertheless, irrespective of the composition of the basal diet, EL and FRM increased milk total trans FA, and altered the profile and relative abundance of cis and trans FA. Further research is required to identify and characterize the underlying mechanisms responsible for the interactions between the basal diet and oilseed supplements, and the influence of these factors on the profile of conjugated FA in milk fat.

\section{ACKNOWLEDGMENTS}

The authors thank M. Barbet and the team of the Monts d'Auvergne experimental unit of Orcival (INRA, UE1296) for the feeding, milking, and diligent management of experimental cows; P. Capitan, D. Bany, C. Delavaud, and E. Tixier (INRA, UR1213), as well as A. Honkanen and P. Kairenius (MTT, Animal Production Research, Jokioinen, Finland) for technical support during the analysis of milk FA composition; and J. A. A. Pires (INRA, UR1213) for helpful discussions on statistical analyses. This research was supported in part, by the European TRUEFOOD program (Traditional United Europe Food), an integrated project funded by the European Commission under the 6th Framework Program for RTD (Contract No. FOODCT-2006-016264). S. Lerch acknowledges and greatly appreciates the financial support of a $\mathrm{PhD}$ studentship provided by In Vivo NSA (Paris, France), ONIDOL (Paris, France), and ANRT (Association Nationale de la Recherche Technique, Paris, France) along a CIFRE fellowship (Convention Industrielle de Formation à la Recherche en Entreprise), and funding awarded by the Center for International Mobility (CIMO, Finland) to support an internship at MTT, Animal Production Research (Jokioinen, Finland).

\section{REFERENCES}

AFNOR (Association Française de Normalisation). 1983. Sensory Analysis. Methodology. Triangle test NF V 09-013. Association Française de Normalisation, La Plaine St-Denis, France.

Akraim, F., M. C. Nicot, R. Juaneda, and F. Enjalbert. 2007. Conjugated linolenic acid (CLnA), conjugated linoleic acid (CLA) and other biohydrogenation intermediates in plasma and milk fat of cows fed raw or extruded linseed. Animal 1:835-843.

AOAC (Association of Official Analytical Chemists). 1997. Official Methods of Analysis. 16th ed. AOAC Int., Gaithersburg, MD.

Bayourthe, C., F. Enjalbert, and R. Moncoulon. 2000. Effects of different forms of canola oil fatty acids plus canola meal on milk composition and physical properties of butter. J. Dairy Sci. 83:690-696.

Brouwer, I. A., A. J. Wanders, and M. B. Katan. 2010. Effect of animal and industrial trans fatty acids on HDL and LDL cholesterol levels in humans - A quantitative review. PLoS ONE 5:e9434. 
Chazal, M.-P., and Y. Chilliard. 1986. Effect of stage of lactation, stage of pregnancy, milk yield and herd management on seasonal variation in spontaneous lipolysis in bovine milk. J. Dairy Res. 53:529-538.

Chazal, M. P., Y. Chilliard, and J. B. Coulon. 1987. Effect of nature of forage on spontaneous lipolysis in milk from cows in late lactation. J. Dairy Res. 54:13-18.

Chilliard, Y., F. Glasser, A. Ferlay, L. Bernard, J. Rouel, and M. Doreau. 2007. Diet, rumen biohydrogenation and nutritional quality of cow and goat milk fat. Eur. J. Lipid Sci. Technol. 109:828855 .

Chilliard, Y., and G. Lamberet. 1984. Milk lipolysis: Various types, mechanisms, factors of variation, practical significance. Lait 64:544-578.

Chilliard, Y., C. Martin, J. Rouel, and M. Doreau. 2009. Milk fatty acids in dairy cows fed whole crude linseed, extruded linseed, or linseed oil, and their relationship with methane output. J. Dairy Sci. 92:5199-5211.

Collomb, M., H. Sollberger, U. Bütikofer, R. Sieber, W. Stoll, and W. Schaeren. 2004. Impact of a basal diet of hay and fodder beet supplemented with rapeseed, linseed and sunflowerseed on the fatty acid composition of milk fat. Int. Dairy J. 14:549-559.

Egger, P., G. Holzer, S. Segato, E. Werth, F. Schwienbacher, G. Peratoner, I. Andrighetto, and A. Kasal. 2007. Effects of oilseed supplements on milk production and quality in dairy cows fed a hay-based diet. Ital. J. Anim. Sci. 6:395-405.

Fearon, A. M., C. S. Mayne, J. A. M. Beattie, and D. W. Bruce. 2004. Effect of level of oil inclusion in the diet of dairy cows at pasture on animal performance and milk composition and properties. J. Sci. Food Agric. 84:497-504.

Ferlay, A., B. Martin, S. Lerch, M. Gobert, P. Pradel, and Y. Chilliard. 2010. Effects of supplementation of maize silage diets with extruded linseed, vitamin $\mathrm{E}$ and plant extracts rich in polyphenols, and morning v. evening milking on milk fatty acid profiles in Holstein and Montbéliarde cows. Animal 4:627-640.

Fievez, V., E. Colman, J. M. Castro-Montoya, I. Stefanov, and B. Vlaeminck. 2012. Milk odd- and branched-chain fatty acids as biomarkers of rumen function-An update. Anim. Feed Sci. Technol. 172:51-65.

Givens, D. I., K. E. Kliem, D. J. Humphries, K. J. Shingfield, and R. Morgan. 2009. Effect of replacing calcium salts of palm oil distillate with rapeseed oil, milled or whole rapeseeds on milk fattyacid composition in cows fed maize silage-based diets. Animal 3:1067-1074.

Glasser, F., A. Ferlay, and Y. Chilliard. 2008a. Oilseed lipid supplements and fatty acid composition of cow milk: A meta-analysis. J. Dairy Sci. 91:4687-4703.

Glasser, F., A. Ferlay, M. Doreau, P. Schmidely, D. Sauvant, and Y. Chilliard. 2008b. Long-chain fatty acid metabolism in dairy cows: A meta-analysis of milk fatty acid yield in relation to duodenal flows and de novo synthesis. J. Dairy Sci. 91:2771-2785.

Gonthier, C., A. F. Mustafa, D. R. Ouellet, P. Y. Chouinard, R. Berthiaume, and H. V. Petit. 2005. Feeding micronized and extruded flaxseed to dairy cows: Effects on blood parameters and milk fatty acid composition. J. Dairy Sci. 88:748-756.

Halmemies-Beauchet-Filleau, A., T. Kokkonen, A. M. Lampi, V. Toivonen, K. J. Shingfield, and A. Vanhatalo. 2011. Effect of plant oils and camelina expeller on milk fatty acid composition in lactating cows fed diets based on red clover silage. J. Dairy Sci. 94:4413-4430.

Hristov, A. N., C. Domitrovich, A. Wachter, T. Cassidy, C. Lee, K. J. Shingfield, P. Kairenius, J. Davis, and J. Brown. 2011. Effect of replacing solvent-extracted canola meal with high-oil traditional canola, high-oleic acid canola, or high-erucic acid rapeseed meals on rumen fermentation, digestibility, milk production, and milk fatty acid composition in lactating dairy cows. J. Dairy Sci. 94:4057-4074.

INRA (Institut National de la Recherche Agronomique). 2007. Alimentation des bovins, ovins et caprins. Besoins des Animaux-Valeur des aliments-Table INRA 2007. INRA, Versailles, France.

Jellema, A., M. Anderson, W. Heeschen, S. Kuzdzal-Savoie, E. C. Needs, G. Suhren, and A. van Reusel. 1991. Determination of free fatty acids in milk and milk products. Vol. 265. Bull. IDF. International Dairy Federation. Brussels, Belgium.

Lawless, F., J. J. Murphy, D. Harrington, R. Devery, and C. Stanton. 1998. Elevation of conjugated cis-9, trans-11-octadecadienoic acid in bovine milk because of dietary supplementation. J. Dairy Sci. 81:3259-3267.

Lerch, S., A. Ferlay, D. Pomiès, B. Martin, J. A. A. Pires, and Y. Chilliard. 2012. Rapeseed or linseed supplements in grass-based diets: Effects on dairy performance of Holstein cows over two consecutive lactations. J. Dairy Sci. 95:1956-1970.

Loor, J. J., A. Ferlay, A. Ollier, and Y. Chilliard. 2005. Relationship among trans and conjugated fatty acids and bovine milk fat yield due to dietary concentrate and linseed oil. J. Dairy Sci. 88:726-740.

Loor, J. J., K. Ueda, A. Ferlay, Y. Chilliard, and M. Doreau. 2004. Biohydrogenation, duodenal flow, and intestinal digestibility of trans fatty acids and conjugated linoleic acids in response to dietary forage:concentrate ratio and linseed oil in dairy cows. J. Dairy Sci. 87:2472-2485.

Martin, B., S. Lerch, A. Ferlay, I. Verdier-Metz, A. Cornu, M. C. Montel, P. Pradel, and Y. Chilliard. 2009. Extruded linseed and antioxidant supplementation of dairy cows diets: What are the influences on the milk and cheese sensory quality? Pages 14-15 in 9th International meeting on mountain cheeses. INRA, SainteEulalie, France.

Mihhejev, K., M. Henno, M. Ots, E. Rihma, P. Elias, S. Kuusik, and O. Kart. 2007. Effects of fat-rich oil cakes on cheese fatty acid composition, and on cheese quality. Vet. Zootec. 40:55-61.

Moss, A. 2002. The effects of long-term feeding of extracted rapeseed meal and whole rapeseed on the physical and financial performance, health and welfare of high yielding dairy cows. HGCA Project Report. HGCA, Kenilworth, Warwickshire, UK.

Murphy, J. J., J. F. Connolly, and G. P. McNeill. 1995. Effects on cow performance and milk fat composition of feeding full fat soybeans and rapeseeds to dairy cows at pasture. Livest. Prod. Sci. $44: 13-25$

Murphy, J. J., G. P. McNeill, J. F. Connolly, and P. A. Gleeson. 1990. Effect on cow performance and milk fat composition of including full fat soyabeans and rapeseeds in the concentrate mixture for lactating dairy cows. J. Dairy Res. 57:295-306.

Neves, C. A., W. B. R. dos Santos, G. T. D. Santos, D. C. da Silva, C. C. Jobim, F. S. Santos, J. V. Visentainer, and H. V. Petit. 2009. Production performance and milk composition of dairy cows fed extruded canola seeds treated with or without lignosulfonate. Anim. Feed Sci. Technol. 154:83-92.

Palmquist, D. L., A. L. Lock, K. J. Shingfield, and D. E. Bauman. 2005. Biosynthesis of conjugated linoleic acid in ruminants and humans. Adv. Food Nutr. Res. 50:179-217.

Rego, O. A., S. P. Alves, L. M. S. Antunes, H. J. D. Rosa, C. F. M. Alfaia, J. A. M. Prates, A. R. J. Cabrita, A. J. M. Fonseca, and R. J. B. Bessa. 2009. Rumen biohydrogenation-derived fatty acids in milk fat from grazing dairy cows supplemented with rapeseed, sunflower, or linseed oils. J. Dairy Sci. 92:4530-4540.

Shingfield, K. J., L. Bernard, C. Leroux, and Y. Chilliard. 2010. Role of trans fatty acids in the nutritional regulation of mammary lipogenesis in ruminants. Animal 4:1140-1166.

Shingfield, K. J., Y. Chilliard, V. Toivonen, P. Kairenius, and D. I. Givens. 2008. Trans fatty acids and bioactive lipids in ruminant milk. Pages 3-65 in Bioactive Components of Milk. Vol. 606. Springer-Verlag Berlin, Berlin, Germany.

Stanton, C., F. Lawless, G. Kjellmer, D. Harrington, R. Devery, J. F. Connolly, and J. Murphy. 1997. Dietary influences on bovine milk cis-9,trans-11-conjugated linoleic acid content. J. Food Sci. 62:1083-1086

Sukhija, P. S., and D. L. Palmquist. 1988. Rapid method for determination of total fatty acid content and composition of feedstuffs and feces. J. Agric. Food Chem. 36:1202-1206.

Urquhart, A., A. M. Cadden, and P. Jelen. 1984. Quality of milk and butter related to canola based protected lipid feed supplement. Milchwissenschaft 39:1-6 